\title{
EXPOSING THE COMPETITION, CO-OPETITION, AND COOPERATION PROCESS OF CONSUMERS INA RETAIL SHOPPING CONTEXT
}

\author{
Bridget Satinover Nichols, Northern Kentucky University, USA
}

\begin{abstract}
Competing is an experiential attribute that is (and has the potential to be) present in many shopping and consumer behavior situations. Although researchers have identified personality traits and situational circumstances as drivers of general competitive consumer behaviors (Mowen 2004), competitive shopping itself has not garnered significant attention. Meanwhile, evidence of consumers actively competing with each other can be found in scarcity-laden shopping situations like Black Friday, new product releases like Apple's iPad and iPhone, and during times of threat or fear, such as when hurricane or snowstorm forecasts drive people to hoard gasoline and staple foods. Competition for consumer goods receives the most attention under circumstances of scarcity, which can be a result of several supply-demand functions (Gierl et al. 2008). But what happens when people compete for scarce goods? Researchers contend that "...scarcity hinders our ability to think...when we watch something we want become less available...a physical agitation sets in....the blood comes up, the focus narrows.... the cognitive and rational side retreats.... cognitive processes are suppressed.... thoughtful analysis of the situation becomes less available... and brain clouding [occurs] (Cialdini 1993, p. 266).”

The subject of consumer competition and cooperation is important because the manner in which customers interact with one another can have significant implications for a retailer. As Martin (1996, p. 17) points out, "relationships between a business and its consumer customers are enhanced when the business' customers interact with one another in a satisfying (or at least tolerable) manner." This is echoed by research showing that shared retail spaces can influence customers' satisfaction with their overall experience (Grove \& Fisk 1997).

Competition has rarely been considered in the consumer domain, despite the prevalence of competitive behaviors in everyday life. To address this lack of attention, a Grounded Theory study of was conducted to better understand the experiences of people who were engaged in a competitive retail shopping event. A sample of shoppers from Filene's Basements Running of the Brides event comprised the informant base, who participated in depth interviews. Specifically, the findings explain the manner in which retail customers shift from competive thoughts and behaviors, to cooperative ones with other retail customers. Three complimentary "trajectories" help explain how this takes place. These trajectories represent 1) an evolving environment, 2) changing relations with opponents, and 3) shifting and intensifying emotions. Each trajectory is dynamic and interrelated. Together, the evolving atmosphere, shifting and intensifying emotions, and changing relationships created a synergistic effect enabling participants to transition from acts of competing to acts of cooperating, which encompass social relationships involving conflict and cohesion, respectively. For a set of participants, cooperation led to acts of charity and compassion. Understanding how consumers engage in competition, and consequently cooperation, should be of considerable interest to retailers wishing to execute competitively natured promotions. The findings also indicate the presence of coopetition, a situation when rivals are competiting and cooperating at the same time. Co-opetition signified an important step between competiting and cooperating. For consumer theorists, this study offers insights into social behavioral processes.
\end{abstract}

References available upon request 